\title{
Subjetividade, trabalho e ação
}

\author{
Christophe Dejours, DIRETOR \\ Laboratoire de Psychologie du Travail et de l'Action \\ Conservatoire National des Arts et Métiers \\ 41, rue Gay-Lussac \\ 75005 Paris França \\ E-mail: dejours@cnam.fr
}

\begin{abstract}
Resumo
Este artigo traz algumas questões para o debate sobre as relações entre trabalho e subjetividade. Nessa perspectiva o trabalho é aquilo que implica, do ponto de vista humano, o fato de trabalhar: gestos, saber-fazer, um engajamento do corpo, a mobilização da inteligência, a capacidade de refletir, de interpretar e de reagir às situações; é o poder de sentir, de pensar e de inventar. O real do trabalho sempre se manifesta afetivamente para o sujeito, aí se estabelece uma relação primordial de sofrimento, experimentada pelo sujeito, corporificada. Trabalhar é preencher a lacuna entre o prescrito e o real. Por isto é que uma parte importante do trabalho efetivo permanece na sombra, não podendo, então, ser avaliado. Outra questão abordada é sobre os acordos firmados entre os trabalhadores no seio do coletivo, de uma equipe ou de um ofício, que têm sempre uma vetorização dupla: de uma parte, um objetivo de eficácia e de qualidade do trabalho; de outra parte, um objetivo social. É proposta também uma discussão entre a teoria psicodinâmica do trabalhar, onde a centralidade do trabalho é um dos seus alicerces e a teoria psicanalítica onde esta questão não é abordada diretamente.
\end{abstract}

\section{Palavras-chave}

Subjetividade e trabalho, sofrimento, prescrito e real, centralidade do trabalho

\section{Subjectivity, work and action}

\begin{abstract}
This paper produces some issues for debate on the relationships between work and subjectivity. Under this perspective, work implies, from a human point of view, the fact of working: gestures, know-how, a commitment of the body, the mobilization of intelligence, the ability to reflect, to interpret and to react to situations; it is the power of feeling, of thinking and of inventing. Actual work is always affectively manifested to the subject, whereby a primordial distress relationship is established, experienced by the subject, embodied. To work is to fill the gap between the prescribed and the real. This is why an important part of the effective work remains in the shade, and cannot, therefore, be assessed. Another question concerns the agreements built by workers within the collective of a team or of a job, which always present a double vectorization: from the one hand, a work efficacy and quality goal; on the other hand, a social goal. A discussion of the psychodynamics of work theory is also proposed, where the work centrality is one of their pillars as well as the psychoanalytical theory, where this issue is not directly approached.
\end{abstract}

\section{Key words}

Subjectivity and work, suffering, prescribed and real, work centrality. 


\section{INTRODUĈ̣̃O}

Gostaria, neste texto, de tentar expor a contribuição que a psicodinâmica do trabalho pode dar à análise das relações entre trabalho e subjetividade. As implicações desta análise são de duas ordens: de uma parte, compreender as conseqüências humanas da virada neoliberal; de outra, enriquecer a concepção da ação no campo político. Sustentarei a idéia de que o caminho que permite associar a subjetividade à teoria da ação passa por uma análise precisa das relações entre o trabalho e a vida.

Para começar, a psicodinâmica do trabalho é uma disciplina clínica que se apóia na descrição e no conhecimento das relações entre trabalho e saúde mental; a seguir, é uma disciplina teórica que se esforça para inscrever os resultados da investigação clínica da relação com o trabalho numa teoria do sujeito que engloba, ao mesmo tempo, a psicanálise e a teoria social.

\section{O QUE É O TRABALHO ?}

As controvérsias entre as disciplinas - sociologia, economia, ergonomia, psicologia, engenharia - circunscrevem-se a concepções muito diferentes a respeito do trabalho. Para alguns, trata-se antes de tudo de uma relação social (do tipo: relação salarial); para outros, trata-se, sobretudo, do emprego; e para outros ainda, trata-se de uma atividade de produção social, etc.

Para nós, a partir do olhar clínico, o trabalho é aquilo que implica, do ponto de vista humano, o fato de trabalhar: gestos, saber-fazer, um engajamento do corpo, a mobilização da inteligência, a capacidade de refletir, de interpretar e de reagir às situações; é o poder de sentir, de pensar e de inventar, etc. Em outros termos, para o clínico, o trabalho não é em primeira instância a relação salarial ou o emprego; é o «trabalhar», isto é, um certo modo de engajamento da personalidade para responder a uma tarefa delimitada por pressões (materiais e sociais). O que ainda aparece para o clínico como a característica maior do «trabalhar», é que, mesmo que o trabalho seja bem concebido, a organização do trabalho seja rigorosa, as instruções e os procedimentos sejam claros, é impossível atingir a qualidade se as prescrições forem respeitadas escrupulosamente. De fato, as situações comuns de trabalho são permeadas por acontecimentos inesperados, panes, incidentes, anomalias de funcionamento, incoerência organizacional, imprevistos provenientes tanto da matéria, das ferramentas e das máquinas, quanto dos outros trabalhadores, colegas, chefes, subordinados, equipe, hierarquia, clientes, ...

De fato, existe sempre uma discrepância entre o prescrito e a realidade concreta da situação. Esta discrepância entre o prescrito e o real se encontra em todos os níveis de análise entre tarefa e atividade (Daniellou e col., 1989) ou ainda entre a organização formal e organização informal (J. D. Reynaud, 1989) do trabalho. Trabalhar é preencher a lacuna entre o prescrito e o real. Ora, o que é preciso fazer para preencher esta lacuna não tem como ser previsto antecipadamente. $\mathrm{O}$ caminho a ser percorrido entre o prescrito e o real deve ser, a cada momento, inventado ou descoberto pelo sujeito que trabalha. Assim, para o clínico, o trabalho se define como sendo aquilo que o sujeito deve acrescentar às prescrições para poder atingir os objetivos que lhe são designados; ou ainda aquilo que ele deve acrescentar de si mesmo para enfrentar o que não funciona quando ele se atém escrupulosamente à execução das prescrições.

\section{0 real do trabalho}

Como, então, o sujeito que trabalha reconhece esta distância irredutível entre a realidade, de um lado, e de outro as previsões, as prescrições e os procedimentos? Sempre sob a forma de fracasso: o real se revela ao sujeito pela sua resistência aos procedimentos, ao saber-fazer, à técnica, ao conhecimento, isto é, pelo fracasso da mestria. O mundo real resiste. Ele confronta o sujeito ao fracasso, de onde surge um sentimento de impotência, até mesmo de irritação, cólera ou ainda de decepção ou de esmorecimento. O real se apresenta ao sujeito por meio de um efeito surpresa desagradável, ou seja, de um modo afetivo. É sempre afetivamente que o real do mundo se manifesta para o sujeito. Mas ao mesmo momento que o sujeito experimenta afetivamente a resistência do mundo, é a afetividade que se manifesta em si. Assim, é numa relação primordial de sofrimento no trabalho que o corpo faz, simultaneamente, a experiência do mundo e de si mesmo.

\section{Sofrimento e inteligência}

Mas o "trabalhar" não se reduz à experiência "pática" do mundo. O sofrimento afetivo, absolutamente passivo, resultado do encontro com o real ao mesmo tempo que marca uma ruptura da ação, ele não é apenas o resultado ou o fim de um processo que une a subjetividade ao trabalho. $\mathrm{O}$ sofrimento é, também, um ponto de partida. Nesta experiência se concentra a subjetividade. O sofrimento se torna um ponto de origem na medida em que a condensação da subjetividade sobre si mesma anuncia um tempo de dilatação, de ampliação, de uma nova expansão sucessiva a ele. $\mathrm{O}$ sofrimento não é apenas uma conseqüência última da relação com o real; ele é ao mesmo tempo proteção da subjetividade com relação ao mundo, na busca de meios para agir sobre o mundo, visando transformar este sofrimento e encontrar a via que permita superar a resistência do real. Assim, o sofrimento é, ao mesmo tempo, impressão subjetiva do mundo e origem do movimento de conquista do mundo. $\mathrm{O}$ sofrimento, enquanto afetividade absoluta, é a 
origem desta inteligência que parte em busca do mundo para se colocar à prova, se transformar e se engrandecer.

Neste movimento que parte do real do mundo como resistência à vontade e ao desejo, para se concretizar em inteligência e em poder de transformar o mundo - neste movimento então - a própria subjetividade se transforma, se engrandece e se revela a si mesma.

\section{Subjetividade, corpo e sujeito}

Desde a origem da experiência de resistência ao mundo até à intuição da solução prático-técnica e a experimentação de respostas ao real, é sempre o corpo que é envolvido em primeiro lugar. Contrariamente ao que supõe o senso comum, o próprio trabalho intelectual não se reduz a uma pura cognição. Ao contrário, trabalhar passa, primeiro, pela experiência afetiva do sofrimento, do pático. Não existe sofrimento sem um corpo para experimentá-lo. De fato, a inteligência no trabalho nunca é redutível a uma subjetividade que sobrepuja o sujeito. A subjetividade só se experimenta na singularidade irredutível de uma encarnação, de um corpo particular e de uma corporeidade absolutamente única.

Entre a subjetividade e o sujeito, a diferença consiste na insistência sobre a singularidade não somente no plano de uma afetividade, mas, também, no de um vir-a-ser ou até mesmo de um destino, com implicações no registro da saúde e da patologia mental, fundamentalmente interrompidas neste corpo e no seu porvir na experiência do trabalhar.

\section{A inteligência e o corpo}

Uma longa discussão seria necessária para expor as relações entre a inteligência no trabalho e o corpo. A habilidade, a destreza, a virtuosidade e a sensibilidade técnica passam pelo corpo, se capitalizam e se memorizam no corpo e se desenvolvem a partir do corpo. O corpo inteiro - e não apenas o cérebro - constitui a sede da inteligência e da habilidade no trabalho. O trabalho revela que é no próprio corpo que reside a inteligência do mundo e que é, antes de tudo, é antes de tudo pelo seu corpo que o sujeito investe no mundo para fazê-lo seu, para habitá-lo.

No entanto, não se deveria ver, nesta inteligência do corpo, um recurso natural. A própria inteligência do corpo se forma no e pelo trabalho; ela não é inata, mas adquirida no exercício da atividade. A formação desta inteligência passa por uma relação prolongada e perseverante do corpo com a tarefa. Ela passa por uma série de procedimentos sutis de familiarização com a matéria, com as ferramentas e com os objetos técnicos. A habilidade técnica, o sentido técnico, supõe previamente a toda performance, um processo de subjetivação da matéria e dos objetos, o qual passa por um diálogo físico com as reações da matéria e dos objetos, que se pode descrever pelo detalhe, assim como propuseram Böhle e Mikau (1991) na teoria da «atividade subjetivante» - Subjektivierendes Handeln - que busca empréstimos conceituais na fenomenologia, em particular em MerleauPonty (1947). Os gregos, por sua vez, também tinham uma concepção desta inteligência do corpo, denominada mètis, a inteligência astuciosa (Detienne e Vernant, 1974).

Convém insistir: o corpo em questão aqui, este corpo apropriado pelo mundo segundo um processo cuja análise que Michel Henry propõe sob o conceito de «corpopropriação» do mundo, não é o mesmo corpo dos biólogos: é um segundo corpo, o corpo que a gente habita, o corpo que se experimenta afetivamente, o corpo que também está engajado na relação com o outro: gestual, mímica, de sedução, de agressividade, muitas teclas de um repertório de técnicas do corpo - no sentido que Marcel Mauss (1934) dá a este termo - colocadas a serviço da expressão do sentido e da vontade de agir sobre a sensibilidade do outro.

Ao segundo corpo, a este corpo subjetivo que se constitui a partir do corpo biológico, dá-se, em psicanálise, o nome de corpo erógeno. E é exatamente este corpo resultante da experiência mais íntima de si e da relação com o outro que é convocado no trabalhar. saberfazer, um engajamento do corpo, a mobilização da inteligência, a capacidade de refletir, de interpretar e de reagir às situações; é o poder de sentir, de pensar e de inventar,
Ainda é preciso insistir sobre uma particularidade deste processo de apropriação ou de "corpopropriação" do mundo e dos objetos técnicos. Este processo implica a subjetividade por inteiro, porque a subjetividade é una e infrangível. Assim que ela se dissociar, anuncia-se o espectro da doença mental. A "corpopropriação" supõe que se mantenha um comércio prolongado e obstinado com a experiência do fracasso, dos caminhos sem saída, das tentativas vãs, dos ensaios desgostosos, da impotência (Y. Clot, 1995). A "corpopropriação" supõe que o sujeito seja habitado pelo sofrimento do trabalhar, da resistência e das esquivas do mundo ao seu poder e ao seu domínio. Para que se forme 
essa intimidade com a matéria e com os objetos técnicos, é preciso que o sujeito aceite ser habitado pelo trabalhar até nas suas insônias e nos seus sonhos. É a este preço que ele acaba por adquirir esta familiaridade com o objeto do trabalhar, o qual confere à inteligência seu caráter genial, isto é, seu poder de engenhosidade.

Devido a esse fato teremos compreendido que o trabalho não é, como se acredita freqüentemente, limitado ao tempo físico efetivamente passado na oficina ou no escritório. $\mathrm{O}$ trabalho ultrapassa qualquer limite dispensado ao tempo de trabalho; ele mobiliza a personalidade por completo.

\section{Trabalho e visibilidade}

Resumindo, o que acaba de ser descrito a respeito de trabalho é da alçada da subjetividade. Significa dizer que o trabalho, naquilo que ele tem de essencial, não pertence ao mundo visível. Como tudo o que é afetivo, o sofrimento que é a origem da inteligência e que constitui a própria substância do trabalhar - por razões transcendentais, é inacessível à quantificação. $\mathrm{O}$ trabalho não pode ser avaliado, porque só aquilo que pertence ao mundo visível é acessível à experimentação científica, podendo ser objeto de uma avaliação objetiva. De maneira que, o que se avalia, corresponde somente àquilo que é visível (a parte materializada da produção), e que não tem nenhuma proporcionalidade passível de comparação com o trabalho efetivo.

Outras características das situações de trabalho agravam, ainda, a invisibilidade do trabalhar. Como se pode ver, ser inteligente no trabalho implica, sempre, em manter uma certa distância dos procedimentos e das prescrições. Trabalhar bem implica infringir as recomendações, os regulamentos, os processos, os códigos, as ordens de serviço, a organização prescrita. Ora, em numerosas situações de trabalho, o controle e a vigilância dos gestos, dos movimentos, dos modos operatórios e dos procedimentos, são rigorosos, se não severos. De sorte que a inteligência no trabalho está, constantemente, condenada à discrição, até mesmo à clandestinidade, particularmente quando se trata de tarefas que envolvam a segurança das pessoas, das instalações ou riscos para o meio ambiente e para as populações. Por isto é que uma parte importante do trabalho efetivo permanece na sombra, não podendo, então, ser avaliado.

A dificuldade pode ser mostrada facilmente, e se agrava, ainda, no momento em que as atividades de trabalho evoluem na direção das tarefas imateriais, isto é, quando não há mais produção de objetos materiais, tais como automóveis ou máquinas de lavar, em particular no caso das atividades ditas de serviço, onde a parte mais importante do trabalho efetivo é invisível.

A inteligência no trabalho, como vimos antes, é essencialmente a inteligência do corpo, depositada no corpo. De forma que o trabalhador hábil sabe, com freqüência, como colocar em ação sua inteligência, embora nem sempre consiga se dar conta disto. Ele não dispõe de todas as palavras necessárias para descrever este trabalho efetivo e é até mesmo provável que o léxico, a própria língua, seja fundamentalmente deficitário em comparação com esta experiência do corpo (déficit semiótico): (J. Boutet, 1995). A inteligência está, por esta razão, sempre avançada em relação à consciência ou ao conhecimento que o próprio sujeito tem de si mesmo. Tudo que no trabalho efetivo não for simbolizado, não pode, a fortiori, ser objetivado.

Somos então obrigados a concluir, no estágio em que nos encontramos a respeito do conhecimento sobre o trabalho, que nós não sabemos e não podemos avaliar o trabalho.

\section{QUAL SUBJETIVIDADE?}

\section{A subjetividade entre trabalho e sexualidade}

A análise da relação entre subjetividade e trabalho sugere, de acordo com a psicodinâmica do trabalho, que o trabalho de ofício engaja toda a subjetividade. Resta examinar a relação inversa: o que a subjetividade deve ao trabalho? O trabalho é uma prova contingente, entre outras, para a subjetividade? Ou então o trabalho é uma condição necessária para a manifestação da subjetividade? Não é possível responder a esta questão apoiando-se unicamente na psicodinâmica do trabalho. É preciso retornar à própria teoria da subjetividade. Tratando-se de clínica, de saúde e de patologia, é preciso considerar, aqui, a teoria psicanalítica do sujeito. Ora, sabe-se que, em psicanálise, o que está no centro da subjetividade não é o trabalho, mas o sexual (ou a sexualidade). Todavia, já mencionamos a importância do encontro entre o corpo e o real do mundo, assim como ele se concretiza na experiência do trabalho, diante do desenvolvimento da subjetividade. A psicodinâmica do trabalho defende a hipótese segundo a qual o trabalho não é redutível a uma atividade de produção no mundo objetivo. $\mathrm{O}$ trabalho sempre coloca à prova a subjetividade, da qual esta última sai acrescentada, enaltecida, ou ao contrário, diminuída, mortificada. Trabalhar constitui, para a subjetividade, uma provação que a transforma. Trabalhar não é somente produzir; é, também, transformar a si mesmo e, no melhor dos casos, é uma ocasião oferecida à subjetividade para se testar, até mesmo para se realizar.

Precisaríamos de mais tempo para desenvolver o exame das relações entre engrandecimento da subjetividade por meio da intermediação da experiência do trabalho e a exaltação da subjetividade intermediada pela sexualidade, pelo desejo e pelo amor. Nós não podemos examinar esta relação no contexto deste artigo. Nos ateremos, então, a assinalar os diferentes caminhos teóricos que deveriam ser perpassados para se chegar a uma síntese dos dados. A contradição entre centralidade do trabalho e centralidade da 
sexualidade, sob o ponto de vista do acontecimento e do desenvolvimento da subjetividade, constitui a dificuldade teórica maior. Na teoria psicodinâmica do trabalhar, o desenvolvimento da subjetividade passa pela relação entre o sofrimento e o real. Na teoria psicanalítica do sujeito, o desenvolvimento da subjetividade passa, antes de tudo, pelas pulsões e seus destinos. Encontrar uma resposta teórica para o paradoxo da dupla centralidade suporia zerar as relações entre sofrimento e pulsão, de uma parte, e de outra, entre o real do mundo e o inconsciente.

Pode ser - mas isto ainda precisa ser demonstrado - que as relações entre sofrimento e pulsão sejam bem mais estreitas do que se acredita de imediato. Sofrimento e pulsão poderiam, precisamente, encontrar um denominador comum no trabalho, de uma parte, e de outra, no corpo. Freud, com efeito, definiu a pulsão como «a quantidade de exigência de trabalho imposta ao psiquismo devido as suas relações com o corpo» (Freud, 1915). Esta analogia, nos termos utilizados tanto em psicodinâmica do trabalho quanto em psicanálise, só pode ser heurística mediante o paradoxo da dupla centralidade, e após uma arqueologia exaustiva da noção de trabalho na metapsicologia freudiana. Tratar-se-ia, mais especificamente, de precisar os elos semânticos entre o Arbeit freudiano, assim como ele se dá por meio das noções de Traumarbeit (trabalho do sonho), Trauerarbeit (trabalho de luto), Durcharbeiten (perlaboração), Verdrängungsarbeit (trabalho de recalque), Arbeitsanforderung (exigência de trabalho), Verdichtungsarbeit (trabalho da condensação), etc., e o trabalho no sentido clássico de produção - poièsis.

$\mathrm{Na}$ falta de desenvolvimento suficiente, pediremos ao leitor o benefício da dúvida. Não lhe pedimos para admitir como verdadeiro, mas somente como possível, o que é comum nos conceitos de Arbeit e o trabalhar (e não o trabalho). Se for o caso, o paradoxo da dupla centralidade se resolveria com uma exegese do conceito de pulsão a partir da definição dada por Freud em 1915, à luz das contribuições da teoria do trabalhar originadas na clínica.

\section{Subjetividade, trabalho e ação}

Por consequiência, falar de centralidade do trabalho no funcionamento psíquico implicaria restabelecer uma relação de consubstancialidade entre trabalho e subjetividade. O trabalho adquiriria, então, um estatuto psíquicoantropológico por inteiro. Qual estatuto? Aquele de prova eletiva da revelação da subjetividade a ela mesma. O trabalhar seria uma condição transcendental de manifestação absoluta da vida.
É em razão deste estatuto do trabalhar em relação à vida que a questão dos laços entre trabalho e subjetividade (e da experiência afetiva fundamental do sofrimento na qual ela se manifesta) deveria encontrar um lugar a sua altura na teoria da ação e no registro do político. Com a evolução do trabalhar, sob o império das novas formas de organização do trabalho, de gestão e de administração específicos do neoliberalismo é, nolens volens, o futuro do homem que está comprometido. Colocar a questão da subjetividade na teoria política é levantar a questão do lugar que se dá à vida na própria concepção de ação. físico efetivamente passado na oficina ou no escritório. O trabalho ultrapassa qualquer limite dispensado ao tempo de trabalho; ele mobiliza a personalidade por completo.

\section{II - A SUBJETIVIDADE ENTRE EXPERIÊNCIA SINGULAR E AC̣ÃO COLETIVA}

\section{Inteligência no singular e inteligência no plural}

Até aqui simplificamos o problema posto pelo trabalhar, ao analisá-lo, essencialmente, como uma experiência solipsista da relação de si para si. Mas o trabalho usual não se apresenta somente desta maneira. No contexto contemporâneo - e talvez já desde há muito tempo - as situações ordinárias de trabalho não podem ser descritas como a justaposição de experiências e de inteligências singulares. Porque, via de regra, trabalha-se para alguém: para um patrão, para um chefe ou um superior hierárquico, para seus subordinados, para seus colegas, para um cliente, etc. O trabalho não é apenas uma atividade; ele é, também, uma forma de relação social, o que significa que ele se desdobra em um mundo humano caracterizado por relações de desigualdade, de poder e de dominação. Trabalhar é engajar sua subjetividade num mundo hierarquizado, ordenado e coercitivo, perpassado pela luta para a dominação. Assim o real do trabalho não é somente o real da tarefa, isto é, aquilo que, pela experiência do corpo a corpo com a matéria e com os objetos técnicos, se dá a conhecer ao sujeito pela sua resistência a ser dominado. Trabalhar é, também, fazer a experiência da resistência do mundo social; e, mais precisamente, das relações sociais, no que se refere ao desenvolvimento da inteligência e da subjetividade. O real do trabalho, não é somente o real do mundo objetivo; ele é, também, o real do mundo social. 
Lendo os parágrafos precedentes, talvez tenhamos antecipado alguns dos desafios para aquele que se preocupa com a organização do trabalho devido ao ressurgimento da inteligência do trabalho. Aquilo que, do trabalhar, não pertence ao mundo visível, pois provém da subjetividade, aquilo que, tendo sido acrescentado, seja, talvez, voluntariamente dissimulado ao olhar do outro pelo sujeito que trabalha (em vista de se proteger das sanções que podem ameaçar a sua inteligência, uma vez que ela leva a cometer infrações relacionadas às prescrições e aos procedimentos), pode engendrar sérios problemas de gestão técnica. $\mathrm{O}$ que aconteceria se cada um, por sua vez, trabalhasse inteligentemente, a sua maneira, de acordo com seus próprios gostos, seu talento inventivo ou sua engenhosidade? De fato, as inteligências singulares podem franquear vias fortemente diferenciadas em saber-fazer, habilidades e técnicas individuais, apresentando, em contrapartida, um poder de divergência entre os estilos de trabalho, com forte risco de desestabilizar a coesão do coletivo de trabalho. Para corrigir os temidos riscos de contradição e de conflito entre as inteligências, se é forçado a compensar o poder de desorganização dos estilos muito singularizados de trabalho, pela coordenação das inteligências.

\section{Coordenação e cooperação}

Mas a coordenação, por sua vez, suscita novas dificuldades. Desde a tradição taylorista, as organizações do trabalho são essencialmente consagradas à divisão social e técnica do trabalho, definindo a cada um tarefas, atribuições e prerrogativas limitadas. Mas, ainda assim, se os trabalhadores respeitassem escrupulosamente estas diretivas dos engenheiros de métodos e dos gestores, nenhuma produção seria possível. Para que o processo de trabalho funcione, é preciso reajustar as prescrições e afinar a organização efetiva do trabalho, diferente da organização prescrita. À coordenação (prescrita), os trabalhadores respondem com a cooperação (efetiva). Entre as duas se interpõe uma série complexa de iniciativas que, quando é eficiente, resulta na formação de «regras de ofício», elaboradas pelos trabalhadores, as quais consistem no estabelecimento de acordos entre os membros do coletivo a respeito das maneiras de trabalhar. Trata-se aqui de compromisso entre os estilos de trabalho, entre as preferências de cada trabalhador, de forma a torná-los compatíveis. Chegar a este resultado supõe que cada trabalhador, individualmente, se envolva no debate coletivo para nele dar testemunho de sua experiência, esforçando-se para tornar visíveis e inteligíveis suas contribuições, seu saber-fazer, suas habilidades, seus modos operatórios. Não basta que ele dê testemunho de sua atividade efetiva; o que é preciso, ainda, é que ele a torne compreensível e que justifique os distanciamentos que se autoriza em relação aos procedimentos. No melhor dos casos as modali- dades de trabalho singulares são objeto de uma confrontação, de uma comparação, de uma discussão coletiva que permite escolher quais são as aceitáveis e quais devem ser proscritas. Às vezes, é necessário recorrer a arbitragens. No fim das contas, toda esta atividade de confrontação supõe a troca de argumentos fundamentados não somente em considerações técnicas, mas, também, na referência às preferências, aos gostos, à idade, ao sexo, à saúde e aos antecedentes médicos, aos valores, enfim: que seja uma confrontação de argumentos tanto técnicos quanto éticos.

Os acordos firmados entre os trabalhadores no seio do coletivo, de uma equipe ou de um ofício, que se estabelecem sob a forma de acordos normativos e, no máximo, sob a forma de regras de trabalho, têm sempre uma vetorização dupla: de uma parte, um objetivo de eficácia e de qualidade do trabalho; de outra parte, um objetivo social. A cooperação supõe, de fato, um compromisso que é ao mesmo tempo sempre técnico e social. Isto tem a ver com o fato de que trabalhar não é unicamente produzir: é, também, e sempre, viver junto. E o viver junto não é algo evidente; ele supõe a mobilização da vontade dos trabalhadores visando conjurar a violência nos litígios ou os conflitos que podem nascer de desacordos entre as partes sobre as maneiras de trabalhar. Esta atividade complexa é conhecida sob o nome de «atividade deôntica». É graças a esta última que a organização real do trabalho evolui e se adapta, em função da composição do coletivo e da transformação material do processo de trabalho.

Do ponto de vista do engajamento da subjetividade no trabalhar, a cooperação supõe, numa certa medida, uma limitação consentida (ou imposta?) à experiência da inteligência e ao desdobramento da vida singular na atividade. Dar sua contribuição e seu consentimento aos acordos normativos num coletivo implica, então, seguidamente, a renúncia a uma parte do potencial subjetivo individual, em favor do viver junto e da cooperação.

\section{A formação da vontade coletiva}

Consentir em cooperar supõe, pelo menos em parte, reprimir sua inteligência e sua própria subjetividade.

Numerosos conflitos surgem no interior dos coletivos de trabalho, demonstrando que nem sempre a renúncia é facilmente consentida por todos. Alguns recusam estas limitações que ocasionam um sofrimento intolerável ao seu desejo de se colocar à prova sem nenhum outro entrave que os seus próprios limites. O individualismo triunfa, então, com risco de arruinar o coletivo e a cooperação.

Por que se consente participar da cooperação quando se conhece o risco do engajamento na discussão coletiva (atividade deôntica) e da autolimitação da subjetividade?

$\mathrm{Na}$ origem do consentimento encontra-se, geralmente, um das duas variáveis abaixo: 
- Na falta de construção de acordos normativos e de regras de trabalho, o individualismo leva a reiterados conflitos e, às vezes, à violência, de maneira que, no fim das contas, as condições sociais e éticas propícias à prova individual da vida no trabalho são, elas próprias, arruinadas. O trabalho gera, então, sofrimento, frustração, sentimento de injustiça e, eventualmente, patologia. Ele se torna deletério e contribui para destruir a subjetividade, juntamente com as bases da saúde mental. É para conjurar este processo mortífero que se aceitam as renúncias individuais exigidas pela cooperação.

- Ao contrário, a segunda variável está associada aos recursos específicos que o coletivo, às vezes, pode colocar ao serviço do aprimoramento das subjetividades singulares. Testemunhar sua experiência do trabalhar, tornar visíveis as descobertas de sua inteligência e seu saber-fazer é o meio de se obter o reconhecimento dos outros. Pois, para esperar o reconhecimento, é preciso, antes, vencer o obstáculo primordial sobre o qual já falamos longamente, a saber: a invisibilidade do trabalho. Assim que o trabalho efetivo acede à visibilidade, então, aí, o reconhecimento se torna possível. Reconhecimento que passa por julgamentos sobre o fazer, sobre o trabalhar, e não sobre a pessoa daquele que trabalha.

Este ponto é essencial para a psicodinâmica do reconhecimento. É graças a este reconhecimento sobre o fazer que se pode respeitar e manter, apesar disso, relações de cooperação com pessoas com as quais não se simpatiza ou pelas quais se sente até mesmo uma certa aversão. O reconhecimento da qualidade das contribuições singulares no registro do fazer desempenha um papel essencial na conjuração da violência entre os seres humanos. O reconhecimento do fazer confere, como acréscimo àquele que dele se beneficia, um pertencimento: pertencimento a um coletivo, a uma equipe ou a um ofício. Assim, a cooperação é um meio poderoso para conjurar a solidão social temida por muitos homens e mulheres. É neste sentido que a cooperação é, também, uma modalidade essencial para a socialização e a integração a uma comunidade de pertencimento.

Se considerarmos a contribuição que a cooperação pode dar no registro individual e no registro social, poderemos compreender por que é possível constituir-se uma solidariedade fundamental entre a experiência subjetiva que se procura e a implicação coletiva na vontade de dar uma contribuição às condições éticas do viver junto.

Contrariamente a preconceitos que muito pesaram sobre as concepções da ação sindical e política, a referência à subjetividade não é necessariamente nociva à formação da vontade coletiva e à ação. Bem pelo contrário. Compromissos racionais entre subjetividade singular e ações coletivas são possíveis. O ponto de vista fundamental trazido pela psicodinâmica do trabalho à concepção da ação, é que uma ação só é racional se ela considerar o destino da subjetividade no trabalho e se ela se alimentar, ao mesmo tempo, daquilo que, em toda atividade de trabalho, provém da subjetividade. Ou, em outras palavras, a ação coletiva é racional se ela se der como objetivo não somente a luta contra a injustiça, mas explicitamente também, e em primeiro lugar, a celebração da vida. Ainda é preciso sublinhar que é na ação voltada para a melhoria da organização do trabalho que reside, principalmente, se não exclusivamente, a possibilidade de se estabelecer uma continuidade entre a vida, de uma parte, e, de outra, a cultura e até mesmo a própria civilização. Com certeza, é uma outra maneira de reencontrar a centralidade do trabalho abordada no início deste texto: se o intuito da ação política é, de fato, a celebração da vida e não o culto do poder, ou melhor, se a luta contra a dominação tem, de fato, como finalidade a celebração da vida e não o gozo do poder ou a promoção do individualismo consumista, então a ação e a luta deverão se dar como meta fazer da organização do trabalho um objetivo prioritário da deliberação política.

\section{om a evolução do trabalhar, sob o império das novas formas de organização do trabalho, de gestão e de administração específicos do neoliberalismo é, nolens volens, o futuro do homem que está comprometido}

\section{«MAL-ESTAR NA CULTURA»}

A análise aqui proposta visa reconstituir os elos intermediários dos processos, autorizando sustentar a idéia de que é possível manter juntas a subjetividade singular e a ação coletiva na sociedade. No centro destes processos, a relação com o trabalho aparece como decisiva e insubstituível. Busquei mostrar que trabalhar pode ser a prova eletiva da revelação da vida a ela mesma. Mas a relação com o trabalho só oferece esta possibilidade se aquela parte que, no trabalho, vem da subjetividade for reconhecida e respeitada.

A evolução contemporânea das formas de organização do trabalho, de gestão e de administração, depois da virada neoliberal, repousa sobre princípios que sugerem, precisamente, sacrificar a subjetividade em nome da rentabilidade 
e da competitividade. Entre estes princípios extrairei apenas dois (pois uma análise exaustiva da evolução da organização do trabalho seria impossível neste artigo), a título de ilustração.

O primeiro princípio é o recurso sistemático à avaliação quantitativa e objetiva do trabalho. Se, por vezes, criticam-se os métodos de avaliação, a maior parte de nossos contemporâneos admite a legitimidade desta última, porque, vencidos pela dominação simbólica das ciências experimentais, pensam que tudo, neste mundo, é avaliável. Se, como vimos, o essencial do trabalhar releva da subjetividade, o que é avaliado não corresponde ao trabalho. Numerosas avaliações, por vezes bastante sofisticadas, se comparadas à contribuição real daqueles que trabalham, conduzem ao absurdo e a injustiças intoleráveis. Na verdade, não se sabe bem o que se avalia; mas, com certeza, não é o trabalho. Assim, a avaliação funciona, sobretudo, como um meio de intimidação e de dominação. Mas sua vocação primordial é afastar a subjetividade dos debates sobre a economia e o trabalho.

O segundo princípio das novas formas de organização do trabalho, de gestão e de direção das empresas é a individualização e o apelo à concorrência generalizada entre as pessoas, entre as equipes e entre os serviços. Os contratos de objetivos, a avaliação individualizada do desempenho, a concorrência entre os agentes e a precarização das formas de emprego, conduzem ao desenvolvimento de condutas desleais entre pares e à ruína das solidariedades. O resultado destas práticas gerenciais é o isolamento de cada indivíduo, a solidão e a desagregação do viver junto ou, melhor ainda, a desolação no sentido que Hannah Arendt dá a este termo (1951), isto é, o desabamento do solo, e que constitui a razão pela qual os homens reconhecem entre si aquilo que eles têm em comum, aquilo que compartilham e que se encontra no próprio alicerce da confiança dos homens uns nos outros.

As consequiências desses princípios da organização do trabalho são, de um lado, o crescimento extraordinário da produtividade e da riqueza, mas, de outro, a erosão do lugar acordado à subjetividade e à vida no trabalho. Disto resulta um agravamento das patologias mentais decorrentes do trabalho em crescimento em todo o mundo ocidental, o surgimento de novas patologias, em particular os suicídios nos próprios locais de trabalho - o que não acontecia jamais antes da virada neoliberal - e o desenvolvimento da violência no trabalho, a agravação das patologias da sobrecarga, a explosão de patologias do assédio.

Mas, é preciso repetir, nenhuma organização, nenhuma empresa, nenhum sistema funciona por si mesmo, automaticamente, por meio de uma lógica interna qualquer. Para funcionar, todo sistema tem necessidade não somente da obediência dos homens e das mulheres, mas do zelo destes, isto é, da sua inteligência. A evolução contemporânea da organização do trabalho não é uma fatalidade. Ela releva da vontade - e do zelo - dos homens e das mulheres que a fazem funcionar. Se o trabalho pode gerar o pior, como hoje, no mundo humano, ele pode, também, gerar o melhor. Isto depende de nós e de nossa capacidade de pensar as relações entre subjetividade, trabalho e ação, graças a uma renovação conceitual.

Tradução: Heliete Karam, doutora em Psicologia Clínica; e Júlia Abrahão, doutora em Ergonomia

ARENDT. H. (1951): "The Origins of Totalitarism". (Harcourt, Brace and World Inc. New York). Trad Française : "Le système totalitaire. Les origines du totalitarisme". Paris. Seuil. p. 224232 .

BÖHLE. F., MILKAU. B. (1991): Vom Handrad zum Bildschirm. CAMPUS. Institut für Sozialwissenschaftliche Forschung e.v. ISF Müncher.
BOUTET. J. (sous la direction de) (1995): "Parole au travail". L'harmattan. 1 vol. 268 pages.

CLOT, Y, (1995): Le travail sans l'homme? Éditions de la Découverte. Paris. 275 pages.

DANIELLOU. F., LAVILLE. A., TEIGER.C. (1983): Fiction et réalité du travail ouvrier. Documentation Française. Les Cahiers Français. 209: 39-45.
DETIENNE M., VERNANT J.P. (1974): "Les ruses de l'intelligence. La metis chez les Grecs". Flammarion (Paris). 1 vol.

FREUD. S. (1915): Triebe und Triebschicksale, Gesammelte Werke. Fischer Verlaag X. Trad Française: Les Pulsions et leurs destins, in "Métapsychologie". Gallimard. 1952, p 25-66.

HENRY. M. (1987): La Barbarie, essai, Grasset. p 81-85.
MAUSS. M. (1934): Les techniques du corps. In "Sociologie et anthropologie". Edition P.U.F. p.p. 365- 388.

MERLEAU-PONTY (1947): Le primat de la perception et ses conséquences philosophiques. Bull. Soc. fr. Phil, 41, 119-153.

REYNAUD, J-D, (1989): Les règles $d u$ jeu, l'action collective et la régulation sociale. Armand Colin, Paris. 